\title{
Feasibility of adjunct facial motor evoked potential monitoring to reduce the number of false-positive results during cervical spine surgery
}

\author{
Ryuta Matsuoka, MD, ${ }^{1}$ Yasuhiro Takeshima, MD, PhD, ${ }^{1}$ Hironobu Hayashi, MD, PhD, ${ }^{2}$ \\ Tsunenori Takatani, MT, PhD, ${ }^{3}$ Fumihiko Nishimura, MD, PhD, ${ }^{1}$ Ichiro Nakagawa, MD, PhD, ${ }^{1}$ \\ Yasushi Motoyama, MD, PhD, ${ }^{1}$ Young-Su Park, MD, PhD, ${ }^{1}$ Masahiko Kawaguchi, MD, PhD, ${ }^{2}$ and \\ Hiroyuki Nakase, MD, PhD'
}

\begin{abstract}
${ }^{1}$ Department of Neurosurgery, Nara Medical University; ${ }^{2}$ Department of Anesthesiology, Nara Medical University; and ${ }^{3}$ Division of Central Clinical Laboratory, Nara Medical University Hospital, Kashihara, Japan
\end{abstract}

\begin{abstract}
OBJECTIVE False-positive intraoperative muscle motor evoked potential (mMEP) monitoring results due to systemic effects of anesthetics and physiological changes continue to be a challenging issue. Although control MEPs recorded from the unaffected side are useful for identifying a true-positive signal, there are no muscles on the upper or lower extremities to induce control MEPs in cervical spine surgery. Therefore, this study was conducted to clarify if additional MEPs derived from facial muscles can feasibly serve as controls to reduce false-positive mMEP monitoring results in cervical spine surgery.
\end{abstract}

METHODS Patients who underwent cervical spine surgery at the authors' institution who did not experience postoperative neurological deterioration were retrospectively studied. mMEPs were induced with transcranial supramaximal stimulation. Facial MEPs (fMEPs) were subsequently induced with suprathreshold stimulation. The mMEP and subsequently recorded fMEP waveforms were paired during each moment during surgery. The initial pair was regarded as the baseline. A significant decline in mMEP and fMEP amplitude was defined as $>80 \%$ and $>50 \%$ decline compared with baseline, respectively. All mMEP alarms were considered false positives. Based on 2 different alarm criteria, either mMEP alone or both mMEP and fMEP, rates of false-positive mMEP monitoring results were calculated.

RESULTS Twenty-three patients were included in this study, corresponding to 102 pairs of mMEPs and fMEPs. This included 23 initial and 79 subsequent pairs. Based on the alarm criterion of mMEP alone, 17 false-positive results (21.5\%) were observed. Based on the alarm criterion of both mMEP and fMEP, 5 false-positive results $(6.3 \%)$ were observed, which was significantly different compared to mMEP alone (difference $15.2 \% ; 95 \% \mathrm{Cl} 7.2 \%-23.1 \% ; \mathrm{p}<0.01$ ).

CONCLUSIONS fMEPs might be used as controls to reduce false-positive mMEP monitoring results in cervical spine surgery.

https://thejns.org/doi/abs/10.3171/2019.9.SPINE19800

KEYWORDS cervical spine; control; facial nerve; false-positive; intraoperative neuromonitoring; motor evoked potential

$\mathrm{C}$ OMPLEX spine surgery is associated with a significant risk of neurological injury. Thus, preventing postoperative neurological deficits is a major concern for spine surgeons. Many reports ${ }^{6,7,14,30,32,37}$ have indicated the effectiveness of intraoperative neuromonitoring. It is currently becoming a required assistive technique for detecting impending neural damage during neurological surgery, including spine surgery. Muscle motor evoked potential (mMEP) monitoring, developed to monitor the functional integrity of the descending motor pathways, ${ }^{4,13}$ allows for early detection and reversal of spinal cord injury during complex spine surgery. ${ }^{12}$ Nevertheless, concerns about the reliability of intraoperative mMEP monitoring in daily clinical practice remain. The main cause of concern is intraoperative instability of the MMEP waveform due to various nonsurgical interventions such as anesthetic agents, and fluctuations in blood pressure or body temperature, among others. ${ }^{24,25}$ Instability of the mMEP waveform causes false-positive results; ${ }^{22}$ thus, the reliability of intraoperative mMEP monitoring becomes questionable.

ABBREVIATIONS fMEP = facial motor evoked potential; mMEP = muscle motor evoked potential.

SUBMITTED July 11, 2019. ACCEPTED September 23, 2019.

INCLUDE WHEN CITING Published online December 13, 2019; DOI: 10.3171/2019.9.SPINE19800. 


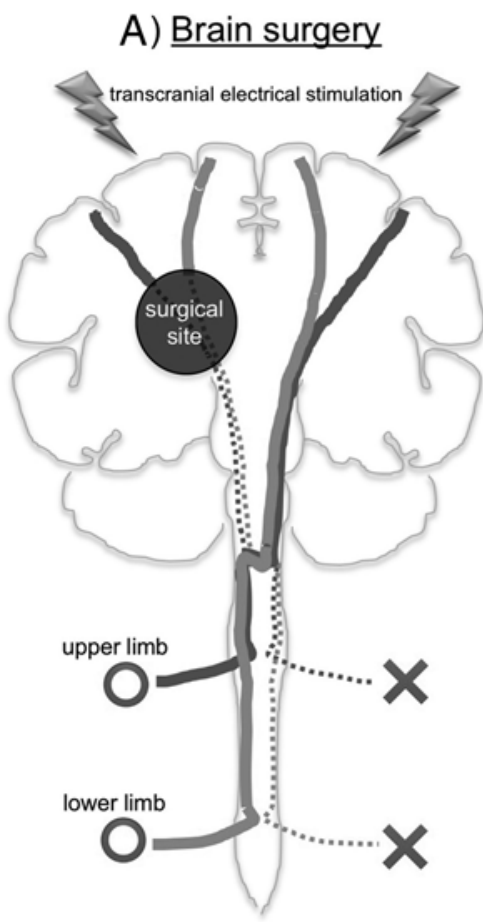

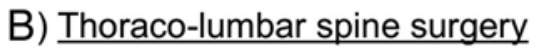

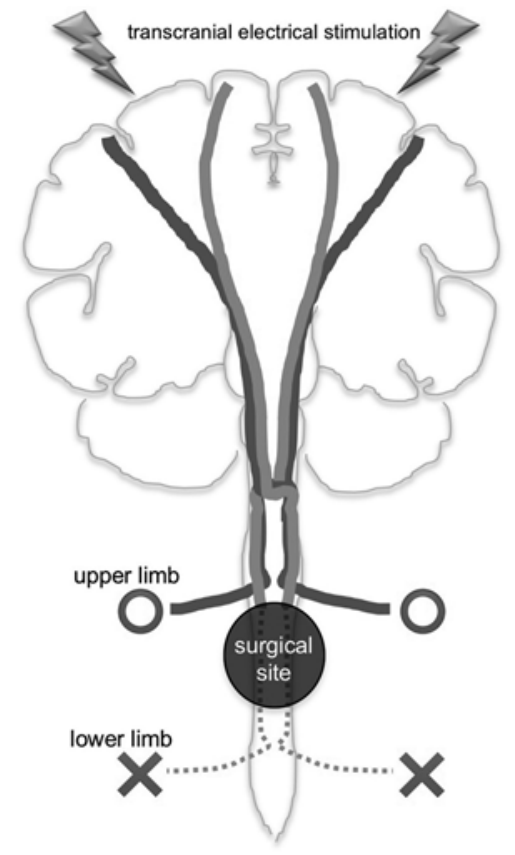

C) Cervical spine surgery

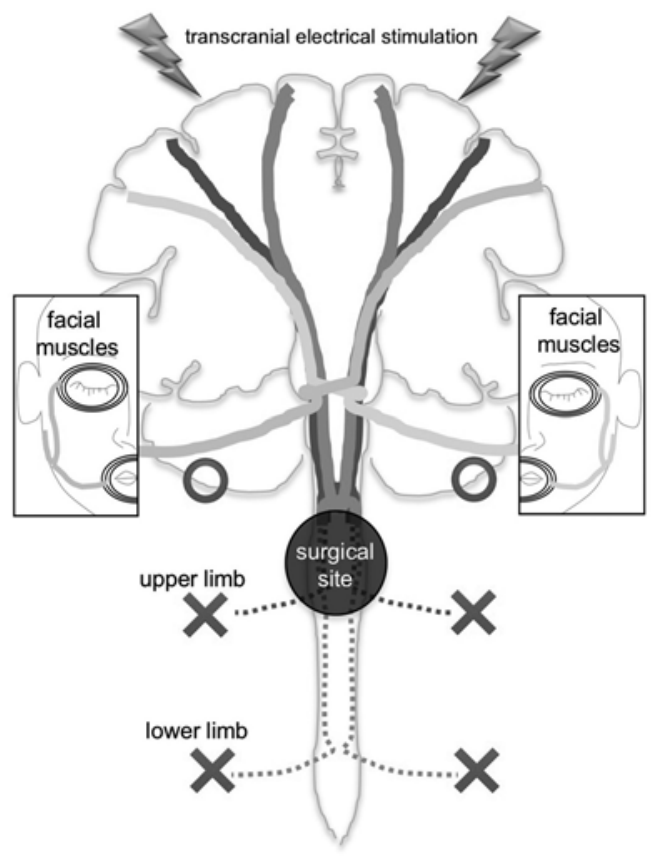

FIG. 1. Schematic drawings of control muscle MEPs. A and B: During brain or thoracolumbar spine surgery, we can interpret waveforms derived from the unaffected contralateral side or upper extremities as controls. C: However, in upper cervical spine surgery, such unaffected control muscles in the extremities typically do not exist.

Control mMEPs from the unaffected side, which are not influenced by surgical manipulation, are useful for identifying truly positive signals by excluding possible indicators of the systemic effects of anesthetic agents and physiological changes during surgery. In general neurosurgical practice, once a significant decrease in mMEP amplitude has been detected intraoperatively on the affected side, we can refer to the control mMEP amplitude derived from the unaffected side to check for systemic effects before giving the surgeon the alarm. For example, in lumbar spine surgery, we can refer to mMEP waveforms from the upper extremities as a control. However, in cervical spine surgery, there are no muscles in the extremities suitable for inducing control mMEPs (Fig. 1).

Transcranial MEPs evoked from the muscles innervated by the facial, vagus, or hypoglossal nerves have been used in intraoperative neuromonitoring of cranial nerve functional integrity in skull base surgery. ${ }^{2,8,33}$ These muscles have recently attracted attention as sources of controls for mMEPs in cervical spine surgery. Therefore, this retrospective study focused on the potential of muscles innervated by the facial nerve to serve as controls during cervical spine surgery. The aim of this study was to clarify if the addition of facial motor evoked potential (fMEP) monitoring to mMEP monitoring of muscles in the extremities is feasible for reducing the number of false-positive results in cervical spine surgery.

\section{Methods}

All experiments were conducted according to the Declaration of Helsinki guidelines. All research protocols were approved by the institutional review board of Nara Medical University. The need for informed consent was waived. We retrospectively studied the medical records of all patients who underwent cervical spine surgery with intraoperative spinal cord monitoring using mMEPs derived from muscles in the extremities and facial muscles in the Department of Neurosurgery at Nara Medical University Hospital between January 2015 and December 2016.

Exclusion criteria were as follows: 1) insufficient fMEP amplitude for all monitored facial muscles $(<10$ $\mu \mathrm{V})$; 2) postoperative neurological deterioration $\left(>1^{\circ}\right.$ of difference on the manual muscle test); and 3) insufficient mMEP amplitude $(<10 \mu \mathrm{V})$.

Clinical data were gathered retrospectively from medical records, radiographic images, anesthetic charts, and preoperative and postoperative neurological examinations. We evaluated patient characteristics and intraoperative neuromonitoring data when the same anesthetic management and techniques documented below were used.

\section{Anesthetic Management}

No medications were given before anesthesia. Induction of anesthesia was achieved with propofol (target-controlled infusion dose of $4.0-6.0 \mu \mathrm{g} / \mathrm{ml}$ ), remifentanil, fentanyl, and rocuronium. Anesthesia was maintained with propofol (target-controlled infusion dose of 2.0-4.0 $\mu \mathrm{g}$ / $\mathrm{ml})$, remifentanil $(0.2-0.4 \mu \mathrm{g} / \mathrm{kg} / \mathrm{min})$, and intermittent fentanyl boluses. Neuromuscular blockade was not used for maintenance of anesthesia. After tracheal intubation, the lungs were ventilated mechanically to maintain a partial end-tidal carbon dioxide pressure of 30 to $40 \mathrm{~mm} \mathrm{Hg}$. 
Anesthetic depth was measured with a bispectral index monitor and maintained between 40 and 60 . The mean arterial pressure was maintained between 70 and $100 \mathrm{~mm}$ $\mathrm{Hg}$ throughout the operation. Core body temperature was maintained between $35.5^{\circ} \mathrm{C}$ and $37.0^{\circ} \mathrm{C}$.

\section{Stimulation and Recording Techniques for MEPs mMEPs From the Extremities}

Transcranial electric stimulation was performed using an intraoperative monitoring system (Neuromaster MEE1232; Nihon Kohden Corp.). The stimulating electrodes consisted of a pair of scalp corkscrew electrodes (NM480B; Nihon Kohden Corp.) at C3 (cathode) and C4 (anode; international 10-20 system). Stimulation consisting of a train of 5 pulses was delivered with an interstimulus interval of $2 \mathrm{msec}$ and duration of $0.2-0.5 \mathrm{msec}$. Stimulus intensity was determined at the beginning of surgery and was set to be just supramaximal to each stimulus. A constant current stimulator (MS-120B; Nihon Kohden Corp.) was initially used up to $200 \mathrm{~mA}$. When the mMEP amplitude was sufficient, constant voltage stimulation was used instead (SEN4100; Nihon Kohden Corp.), up to $500 \mathrm{~V}$. When the mMEP amplitude was insufficient, a posttetanic $\mathrm{MEP}^{10}$ was also used. Compound muscle action potentials were recorded from the skin over the abductor pollicis brevis, tibialis anterior, gastrocnemius, and abductor hallucis bilaterally using disposable surface electrodes (Vitrode V; Nihon Kohden Corp.). The settings of the low- and high-cut filters were $1-5 \mathrm{~Hz}$ and $1.5-3.0 \mathrm{kHz}$, respectively.

\section{Facial Motor Evoked Potentials}

Transcranial stimulation was performed with the same apparatus for fMEPs. For fMEP monitoring, stimulation consisting of a train of 4 pulses was delivered with an interstimulus interval of 1.5-1.7 msec; suprathreshold stimulation was used. Because facial muscles and muscles in the extremities have different reactivity to muscle relaxants, 3,5 confirmation of recovery from muscle relaxants was required. Compound muscle action potentials were recorded from the skin over the orbicularis oculi and orbicularis oris bilaterally by using needle electrodes (NM-31; Nihon Kohden Corp). For the orbicularis oculi and orbicularis oris, the anode and cathode were set on the lateral and medial sides of the muscle just below the orbit or mouth, respectively. Transcranial electrical fMEP stimulation was performed immediately after mMEP stimulation.

\section{Criteria to Check MEPs During the Surgery}

After induction of anesthesia, it was confirmed that neuromuscular blockade had adequately deactivated. If it was inadequate below $80 \%$ in train-of- 4 monitoring, neuromuscular blockade reversal was achieved with sugammadex. Then, baseline mMEPs and fMEPs were recorded. After the start of surgery, MEPs were evoked in the beginning of each surgical phase and at the end of surgery.

\section{Data Collection and Analysis of mMEP and fMEP Waveforms}

All mMEP and fMEP data derived intraoperatively were collected by a neurosurgeon and an anesthesiolo- gist who were not involved in data interpretation of the study. For evaluation of fMEPs, the amplitudes of fMEPs derived from orbicularis oris were preferentially evaluated in each patient. If fMEPs derived from orbicularis oris were unstable, they were replaced by orbicularis oculi fMEPs. mMEP and subsequently recorded fMEP waveforms, evoked in combination as described above, were paired. The initial pair was regarded as the baseline for each patient. Rates of change in amplitude from baseline were calculated for each mMEP and fMEP.

\section{Details About 2 Different Alarm Criteria}

A significant decline in mMEP or fMEP amplitude was defined as a decline of $>80 \%$ or $>50 \%$ compared to the baseline amplitude, respectively. All mMEP alarms were considered false positive, because the patients included in this study had no observed neurological deterioration after cervical spine surgery. Two different alarm conditions, including alarms based on mMEP alone or mMEP and fMEP in combination, were used to evaluate the feasibility of using fMEPs as controls.

Using the alarm criterion based on mMEP alone, the false-positive rate was calculated based on only the criterion for mMEPs. Using the alarm criterion based on mMEP and fMEP in combination, once a decline in mMEP amplitude met the alarm criterion for mMEP alone, the change in fMEP amplitude recorded at the same moment was assessed using the alarm criterion for fMEPs. Next, the decline in mMEP amplitude was determined to be a "true" false-positive result when the change in fMEP amplitude did not meet the fMEP alarm criterion. The decline in mMEP amplitude was determined to be a "false" false-positive result when the change in fMEP amplitude met the fMEP alarm criterion.

\section{Statistical Analysis}

All statistical comparisons were performed using PASW software, version 18 (SPSS, IBM Corp.). The falsepositive rate for mMEP monitoring based on the 2 different diagnostic techniques was calculated separately. The difference in false-positive rates based on the 2 different diagnostic techniques was compared using the McNemar test to assess the feasibility of adding fMEP monitoring to eliminate systemic effects.

\section{Results}

\section{Clinical Characteristics}

Although cervical spine surgery was performed with both intraoperative mMEP and fMEP monitoring in 31 patients during this period, 23 patients without postoperative neurological deterioration were ultimately included in this study (Fig. 2). In these 23 patients, 102 trials of combined mMEP and fMEP monitoring, including 23 initial and 79 subsequent trials, were evaluated.

The characteristics of the study patients who did not have postoperative neurological deterioration are presented in Table 1 . The study population included 15 men and 8 women aged $43-83$ years (mean $\pm \mathrm{SD}, 65.5 \pm 12.1$ years). Most patients had cervical canal stenosis (34.8\%). Five (22\%) underwent surgery via an anterior approach. The mean preoperative and postoperative Japanese Ortho- 


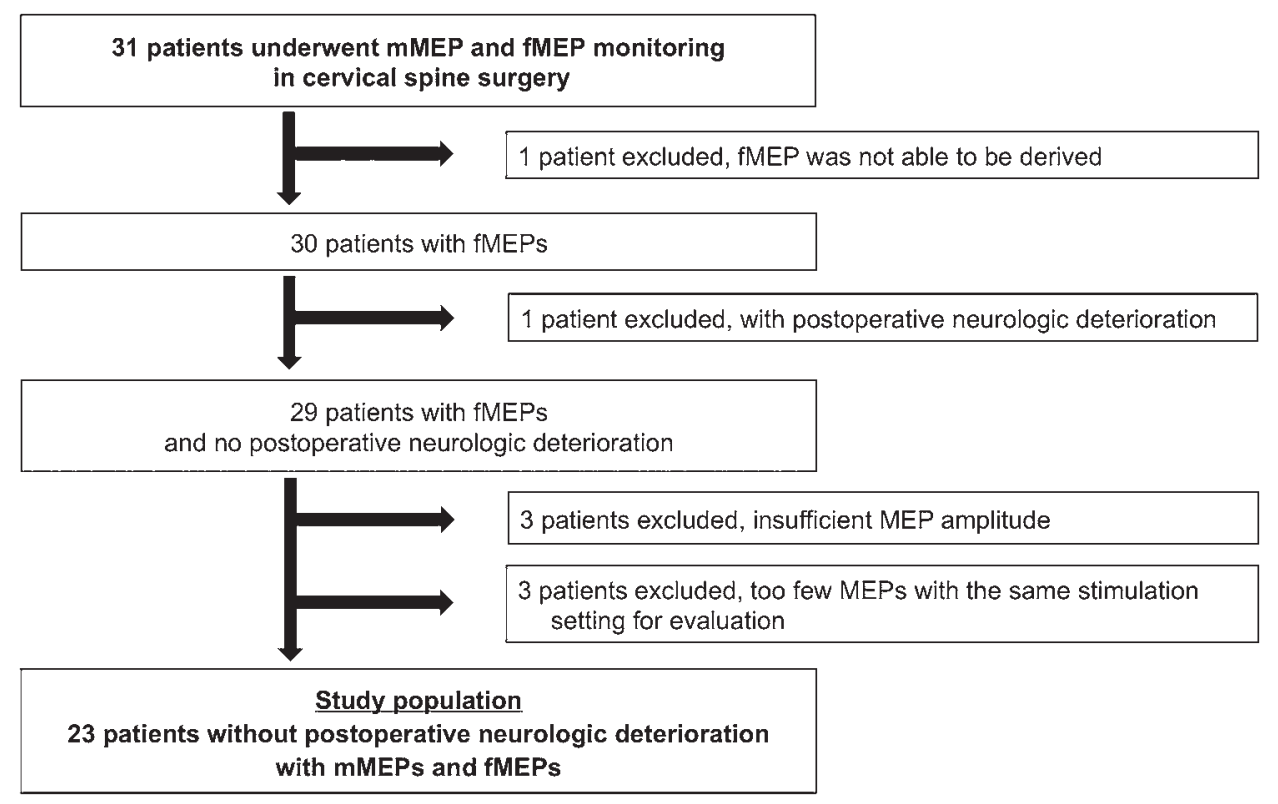

FIG. 2. Flowchart showing the patient selection process of this study. Eight of 31 patients were excluded for various reasons; 23 patients were included in the analysis.

paedic Association scores at discharge were $11.9 \pm 2.9$ and $14.4 \pm 2.2$ (mean $\pm \mathrm{SD}$ ), respectively.

\section{Relationship Between the Number of Alarms Based on mMEP and fMEP Alarm Criteria}

The relationship between the number of alarms based on the mMEP alarm criterion and the addition of the fMEP alarm criterion is shown in Table 2. Based on the mMEP alarm criterion, 17 alarms were observed. Based on the fMEP alarm criterion, 15 alarms were observed. Because the fMEP alarm was issued simultaneously in 12 of 17 alarms based on the mMEP alarm criterion, 12 alarms based on the mMEP alarm criterion satisfied the combined mMEP and fMEP alarm criterion, which was identified as arising from systemic effects such as anesthetic agents and physiological changes. As a result, there were 5 true false-positive results for mMEP monitoring when fMEP monitoring was used as a control.

In terms of the number of patients, 13 patients were affected by at least one of each alarm. In detail, the alarms were involved in 7 of 23 patients based on the mMEP alarm criterion. Based on the additional fMEP criterion, 6 of the 7 patients had the "false" false-positive results, and 4 of the 7 patients also had the "true" false-positive results.

\section{Impact of Adding fMEP Monitoring as a Control for mMEP Monitoring}

A flowchart showing the diagnosis of "true" false-positive mMEP monitoring results based on the alarm criterion for combined mMEP and fMEP is shown in Fig. 3. The false-positive rate for intraoperative mMEP monitoring based on the mMEP alarm criterion alone was $21.5 \%$ (17 of 79 trials), whereas the false-positive rate of intraoperative mMEP monitoring based on the combined mMEP and fMEP alarm criterion was $6.3 \%$ (5 of 79 trials). The difference in the rate of false-positive detection between the 2 alarm criteria was $15.2 \%$ (95\% CI 7.2\%-23.1\%; p < $0.01)$.

\section{Discussion}

This is the first study to evaluate the feasibility of adding fMEPs as controls in order to reduce false-positive mMEP monitoring results during cervical spine surgery. The false-positive rate decreased significantly from $21.5 \%$ to $6.3 \%$ when fMEPs were used as controls. Because mMEPs are sensitive to anesthetic agents, neuromuscular blockade, and fading (gradually decreasing amplitudes and rising thresholds over time during surgery), a valid baseline should be selected accordingly for each distinct phase during operation. ${ }^{26}$ It would be difficult to define multiple mMEP baselines intraoperatively, especially when surgical phases transition seamlessly (e.g., during long intramedullary tumor surgeries). Therefore, adding fMEP monitoring as a control is highly recommended because the added information would be very important.

\section{False-Positive Results as a Major Issue in Intraoperative mMEP Monitoring}

Although mMEPs have been widely used in neurological surgery, ${ }^{20,21}$ intraoperative instability of the mMEP waveform presents a major issue that sometimes causes critical problems such as false-positive results. ${ }^{24}$ Sakaki et al. reported that false positives occurred in 54 of 350 (15.4\%) patients with cervical compression myelopathy when transcranial mMEP monitoring was used; the alarm criterion in this report was defined as waveform disappearance. ${ }^{31} \mathrm{Kim}$ et al. also conducted a study in which 5 of $52(9.6 \%)$ patients undergoing surgery for cervical 
TABLE 1. Clinical characteristics of the 23 study participants

\begin{tabular}{lc}
\hline \multicolumn{1}{c}{ Characteristic } & Value \\
\hline Age, yrs & $65.5 \pm 12.1$ \\
\hline Male sex & $15(65.2 \%)$ \\
\hline Disease & $8(34.8 \%)$ \\
\hline Cervical canal stenosis & $6(26.1 \%)$ \\
\hline Ossification of the posterior longitudinal ligament & $4(17.4 \%)$ \\
\hline Cervical disc herniation & $4(17.4 \%)$ \\
\hline C1/2 subluxation & $1(4.3 \%)$ \\
\hline C2 fracture & \\
\hline Surgical approach & $18(78.3 \%)$ \\
\hline Posterior & $5(21.7 \%)$ \\
\hline Anterior & \\
\hline Highest level & $6(26.1 \%)$ \\
\hline C1 & $0(0 \%)$ \\
\hline C2 & $6(26.1 \%)$ \\
\hline C3 & $5(21.7 \%)$ \\
\hline C4 & $5(21.7 \%)$ \\
\hline C5 & $0(0 \%)$ \\
\hline C6 & $1(4.3 \%)$ \\
\hline C7 & $11.9 \pm 2.9$ \\
\hline JOA score for cervical myelopathy & $14.4 \pm 2.2$ \\
\hline Before surgery & \\
\hline At discharge & \\
\hline VOA Japanese Orthopaedic Association. & \\
\hline & \\
\hline
\end{tabular}

myelopathy had false-positive results; the alarm criterion consisted of an $80 \%$ decline in amplitude. ${ }^{16}$ These falsepositive results should be avoided because they may lead surgeons to make an error in intraoperative judgment or surgical strategy.

Intraoperative mMEP waveforms are impacted by physiological changes (e.g., temperature, blood pressure $)^{24,27}$ as well as systemic effects of anesthetic agents and neuromuscular blockade. To overcome these systemic effects, one technique consists of neuromonitoring potentials directly evoked from the spinal cord, known as Dwaves. Because the $\mathrm{D}$-wave does not involve any synaptic responses and is relatively insensitive to anesthesia, ${ }^{22} \mathrm{com}$ bined $\mathrm{mMEP}$ and $\mathrm{D}$-wave monitoring is recommended to reduce the number of false-positive results..$^{11,17,35}$ However, since the D-wave might reflect some physiological changes, another approach to overcome this issue has been recommended.

\section{Need for a Reference MEP as a Control in Cervical Spine Surgery}

To overcome the instability of intraoperative mMEPs, setting a reference MEP as a control is another popular and effective approach. There are a few reports demonstrating the usefulness of concurrent ipsilateral and contralateral MEP monitoring during brain and spine surgery. ${ }^{24,27,36}$ In these reports, analyzing waveforms elicited from the affected and unaffected hemispheres during surgery al-
TABLE 2. Relationship between the number of alarms based on mMEP alarm criterion and the addition of fMEP alarm criterion

\begin{tabular}{cccc}
\hline & \multicolumn{2}{c}{$>50 \%$ Decline in fMEP Amplitude } & \\
\cline { 2 - 3 } Criterion & $(+)$ & $(-)$ & Total \\
\hline $\begin{array}{c}\text { 80\% decline in extremity } \\
\text { mMEP amplitude }\end{array}$ & & & \\
\hline$(+)$ & 12 & 5 & 17 \\
\hline$(-)$ & 3 & 59 & 62 \\
\hline Total & 15 & 64 & 79 \\
\hline
\end{tabular}

lows for the detection of general effects (e.g., anesthesia, hypotension) on mMEPs,${ }^{36}$ reduces false-positive observations, ${ }^{23}$ and achieves high sensitivity and specificity. Even though monitoring rostral or contralateral MEPs concurrently as controls whenever possible is highly recommended, ${ }^{26}$ the practical effects of adding unaffected MEPs as controls on the rate of false-positive results in brain and spine surgery are not well understood. Moreover, in upper cervical spine surgery, it is extremely difficult to set a reference value based on muscles in the extremities because there are no suitable muscles above the affected level. Therefore, control MEPs recorded as cranially as possible are highly recommended in cervical spine surgery.

Other options for reference muscles as controls in cervical spine surgery include the sternocleidomastoid and muscles of the face and tongue..$^{15,29}$ The sternocleidomastoid may be useful as a reference for cervical spinal disorders only below the C6 level, because its innervation is dominated by the accessory nerve arising from the medulla oblongata to the fifth or sixth segment of the cervical spinal cord. On the other hand, the facial nerve is not involved in spinal cord function. Facial muscles are promising candidates because transcranial fMEP monitoring has recently become recognized and established as a valid method for quantitative monitoring of facial nerve function in skull base surgery, including surgery for vestibular schwannoma. ${ }^{7-9,33}$ One interesting report suggested the possibility of using transcranial MEPs from tongue muscles as controls in cervical spine surgery. ${ }^{15}$ However, there is relatively poor evidence regarding mMEPs from muscles innervated by the hypoglossal nerve.

At our institution, we have empirically adopted fMEPs as controls. We believe it has been beneficial in cervical spine and craniovertebral junction surgery for many years. Adding fMEP monitoring needs only a brief time; electrode placement on facial muscles needs 5 minutes, and additional electrical stimulation for fMEPs needs only 1 second or less. The leads for fMEP monitoring do not get in the way of any operative procedure in the cervical spine. Therefore, we planned this study to confirm the benefit of adding fMEPs as controls in cervical spine surgery.

\section{Criteria Regarding Amplitude Decline for Spinal Cord Monitoring}

The definition of a significant decline in fMEP and mMEP amplitude in the present study was based on past reports. For spinal cord monitoring, MacDonald proposed 


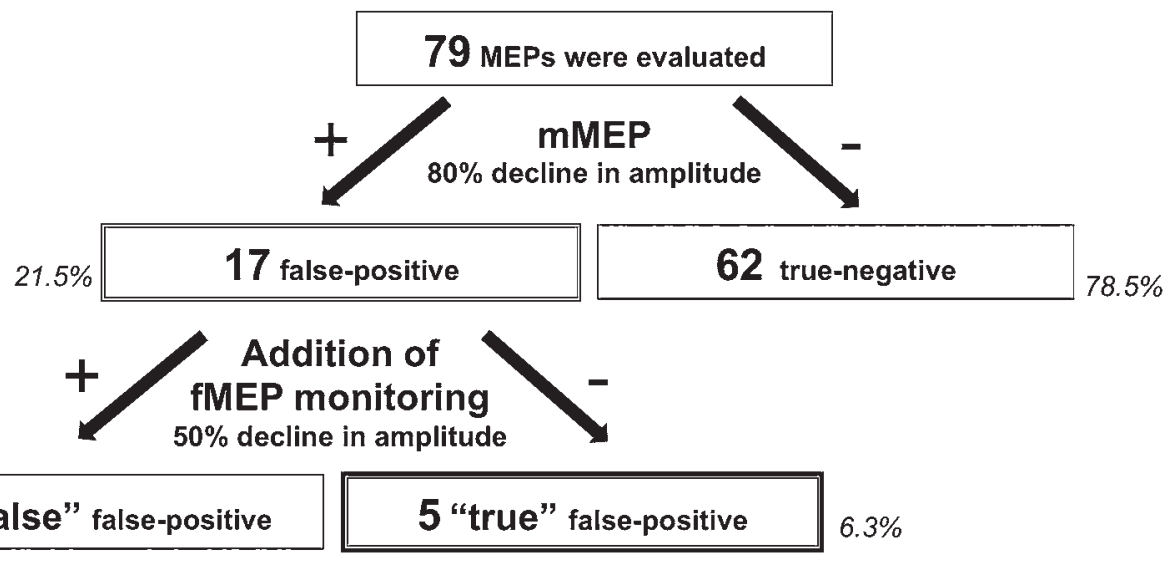

FIG. 3. Flowchart for diagnosing true false-positive mMEP monitoring results. Seventy-nine combined trials of mMEPs and fMEPS were evaluated. False-positive results were observed in 17 trials with mMEP assessment alone. The addition of fMEP assessment led to false-positive results in only 5 trials.

in a review $\operatorname{paper}^{26}$ that a $50 \%$ decline based on supramaximal transcranial electrical stimulation is too sensitive and a more marked decline is required, such as $>80 \%$. However, this cutoff still results in a positive predictive value of only 0.6 ; a substantial proportion of false positives remain. ${ }^{18,19,22,28}$ For brain surgery, it was also noted that a mild $(>50 \%)$ amplitude decline may be a major alarm criterion. For facial nerve monitoring, a 50\% decline is considered a major alarm criterion based on published data. ${ }^{8}$

\section{Possible Adverse Effects of Adding fMEP Monitoring on True-Positive Results}

In this study, adding fMEP monitoring significantly reduced the number of false-positive results. However, there is concern that adding fMEP monitoring might negatively affect the reliability of mMEP monitoring. Because only patients without postoperative neurological deterioration were included in this study, the impact of adding fMEP monitoring on the number of true-positive results could not be analyzed. Thus, there is a possibility that adding fMEP monitoring could conversely reduce the number of true-positive results, but it was not possible to assess this phenomenon in the present study.

However, this might be a minor issue because many studies have demonstrated that fMEP monitoring has a high degree of reliability. ${ }^{2,33,34}$ Akagami et al. reported that facial MEPs predicted immediately satisfactory postoperative facial functioning with a final-to-baseline ratio of $50 \%$. There was a strong correlation between the final-tobaseline MEP ratio and immediate postoperative clinical facial nerve outcome. Moreover, the sensitivity and specificity for the criterion of 50\% reduction in fMEP amplitude were $90 \%$ and $89 \%$, respectively. ${ }^{2}$ Therefore, this highly reliable and established method is unlikely to affect true-positive results in the present study.

\section{Limitations of the Study}

Our study had some limitations. First, this was a retrospective study with a small number of patients. Because we decided to survey MEP waveforms by using electronic medical records over the entire surgical procedure, measurement bias was possible. Second, to the best of our knowledge, no specific complications associated with adding fMEP monitoring have been reported, such as slight scratches or bleeding from the facial recording needles. Third, only false-positive results were assessed in this study. For a comprehensive analysis of intraoperative neuromonitoring, false-positive and false-negative rates, sensitivity, and specificity are all essential endpoints. Moreover, this study did not include patients who developed new postoperative neurological deficits. Therefore, further investigation will be needed to assess the utility of using fMEPs as controls by using data collected from patients who experienced postoperative neurological worsening.

In addition, specific care would be needed to derive fMEPs. Because the amplitudes of fMEPs are very low due to suprathreshold stimulation, meticulous attention to avoid suppressing potentials from facial muscles would be needed to maintain anesthesia. Neuromonitoring technologists should also avoid direct stimulation of facial muscles by stray current, which is induced by strong electrical stimulation. Therefore, it is very important to be attentive to the surgeon's communications with the anesthesiologist and neuromonitoring technologist. Despite these limitations, the present study showed for the first time that mMEP monitoring using fMEPs as controls might lower the false-positive rate in upper cervical spine surgery.

\section{Conclusions}

Adding fMEP monitoring to control for the systemic effects of anesthetic agents and physiological changes might be feasible. Adjunct fMEP monitoring might help reduce the number of false-positive results associated with mMEP monitoring during cervical spine surgery.

\section{References}

1. Abboud T, Schaper M, Dührsen L, Schwarz C, Schmidt NO, Westphal M, et al: A novel threshold criterion in transcranial motor evoked potentials during surgery for gliomas close to the motor pathway. J Neurosurg 125:795-802, 2016 
2. Akagami R, Dong CC, Westerberg BD: Localized transcranial electrical motor evoked potentials for monitoring cranial nerves in cranial base surgery. Neurosurgery 57 (1 Suppl):78-85, 2005

3. Brauer M, Knuettgen D, Quester R, Doehn M: Electromyographic facial nerve monitoring during resection for acoustic neurinoma under moderate to profound levels of peripheral neuromuscular blockade. Eur J Anaesthesiol 13:612-615, 1996

4. Burke D, Hicks RG: Surgical monitoring of motor pathways. J Clin Neurophysiol 15:194-205, 1998

5. Caffrey RR, Warren ML, Becker KE Jr: Neuromuscular blockade monitoring comparing the orbicularis oculi and adductor pollicis muscles. Anesthesiology 65:95-97, 1986

6. Cheng JS, Ivan ME, Stapleton CJ, Quinones-Hinojosa A, Gupta N, Auguste KI: Intraoperative changes in transcranial motor evoked potentials and somatosensory evoked potentials predicting outcome in children with intramedullary spinal cord tumors. J Neurosurg Pediatr 13:591-599, 2014

7. Cosetti MK, Xu M, Rivera A, Jethanamest D, Kuhn MA, Beric A, et al: Intraoperative transcranial motor-evoked potential monitoring of the facial nerve during cerebellopontine angle tumor resection. J Neurol Surg B Skull Base 73:308315,2012

8. Dong CC, Macdonald DB, Akagami R, Westerberg B, Alkhani A, Kanaan I, et al: Intraoperative facial motor evoked potential monitoring with transcranial electrical stimulation during skull base surgery. Clin Neurophysiol 116:588-596, 2005

9. Goto T, Muraoka H, Kodama K, Hara Y, Yako T, Hongo $\mathrm{K}$ : Intraoperative monitoring of motor evoked potential for the facial nerve using a cranial peg-screw electrode and a "threshold-level" stimulation method. Skull Base 20:429434, 2010

10. Hayashi H, Kawaguchi M, Yamamoto Y, Inoue S, Koizumi M, Ueda Y, et al: Evaluation of reliability of post-tetanic motor-evoked potential monitoring during spinal surgery under general anesthesia. Spine (Phila Pa 1976) 33:E994-E1000, 2008

11. Ito Z, Matsuyama Y, Ando M, Kawabata S, Kanchiku T, Kida K, et al: What is the best multimodality combination for intraoperative spinal cord monitoring of motor function? A multicenter study by the Monitoring Committee of the Japanese Society for Spine Surgery and Related Research. Global Spine J 6:234-241, 2016

12. Kalkman CJ, Been HD, Ongerboer de Visser BW: Intraoperative monitoring of spinal cord function. A review. Acta Orthop Scand 64:114-123, 1993

13. Kaneko M, Fukamachi A, Sasaki H, Miyazawa N, Yagishita T, Nukui H: Intraoperative monitoring of the motor function: experimental and clinical study. Acta Neurochir Suppl (Wien) 42:18-21, 1988

14. Kelleher MO, Tan G, Sarjeant R, Fehlings MG: Predictive value of intraoperative neurophysiological monitoring during cervical spine surgery: a prospective analysis of 1055 consecutive patients. J Neurosurg Spine 8:215-221, 2008

15. Kim DG, Jo SR, Youn M, Hyun SJ, Kim KJ, Jahng TA, et al: Corticobulbar motor evoked potentials from tongue muscles used as a control in cervical spinal surgery. Clin Neurophysiol Pract 2:124-129, 2017

16. Kim DH, Zaremski J, Kwon B, Jenis L, Woodard E, Bode R, et al: Risk factors for false positive transcranial motor evoked potential monitoring alerts during surgical treatment of cervical myelopathy. Spine (Phila Pa 1976) 32:3041-3046, 2007

17. Kobayashi K, Ando K, Shinjo R, Ito K, Tsushima M, Morozumi $\mathrm{M}$, et al: Evaluation of a combination of waveform amplitude and peak latency in intraoperative spinal cord monitoring. Spine (Phila Pa 1976) 43:1231-1237, 2018
18. Langeloo DD, Journée HL, de Kleuver M, Grotenhuis JA: Criteria for transcranial electrical motor evoked potential monitoring during spinal deformity surgery A review and discussion of the literature. Neurophysiol Clin 37:431-439, 2007

19. Langeloo DD, Lelivelt A, Louis Journée H, Slappendel R, de Kleuver M: Transcranial electrical motor-evoked potential monitoring during surgery for spinal deformity: a study of 145 patients. Spine (Phila Pa 1976) 28:1043-1050, 2003

20. Legatt AD: Current practice of motor evoked potential monitoring: results of a survey. J Clin Neurophysiol 19:454-460, 2002

21. Legatt AD, Emerson RG: Motor evoked potential monitoring-it's about time. J Clin Neurophysiol 19:383-386, 2002

22. Legatt AD, Emerson RG, Epstein CM, MacDonald DB, Deletis V, Bravo RJ, et al: ACNS Guideline: Transcranial electrical stimulation motor evoked potential monitoring. J Clin Neurophysiol 33:42-50, 2016

23. Lo YL, Dan YF, Teo A, Tan YE, Yue WM, Raman S, et al: The value of bilateral ipsilateral and contralateral motor evoked potential monitoring in scoliosis surgery. Eur Spine J 17 (Suppl 2):S236-S238, 2008

24. Lyon R, Feiner J, Lieberman JA: Progressive suppression of motor evoked potentials during general anesthesia: the phenomenon of "anesthetic fade". J Neurosurg Anesthesiol 17:13-19, 2005

25. MacDonald DB: Intraoperative motor evoked potential monitoring: overview and update. J Clin Monit Comput 20:347-377, 2006

26. MacDonald DB: Overview on criteria for MEP monitoring. $\mathbf{J}$ Clin Neurophysiol 34:4-11, 2017

27. MacDonald DB, Al Zayed Z, Khoudeir I, Stigsby B: Monitoring scoliosis surgery with combined multiple pulse transcranial electric motor and cortical somatosensory-evoked potentials from the lower and upper extremities. Spine (Phila Pa 1976) 28:194-203, 2003

28. MacDonald DB, Skinner S, Shils J, Yingling C: Intraoperative motor evoked potential monitoring - a position statement by the American Society of Neurophysiological Monitoring. Clin Neurophysiol 124:2291-2316, 2013

29. Morishige M, Takeda M, Yamaguchi S, Sugiyama K, Kurisu $\mathrm{K}$ : Application of compound action potential of facial muscles evoked by transcranial stimulation as a reference waveform of motor-evoked potential in spinal surgery. Hiroshima J Med Sci 66:1-5, 2017

30. Park P, Wang AC, Sangala JR, Kim SM, Hervey-Jumper S, Than KD, et al: Impact of multimodal intraoperative monitoring during correction of symptomatic cervical or cervicothoracic kyphosis. J Neurosurg Spine 14:99-105, 2011

31. Sakaki K, Kawabata S, Ukegawa D, Hirai T, Ishii S, Tomori $\mathrm{M}$, et al: Warning thresholds on the basis of origin of amplitude changes in transcranial electrical motor-evoked potential monitoring for cervical compression myelopathy. Spine (Phila Pa 1976) 37:E913-E921, 2012

32. Sala F, Bricolo A, Faccioli F, Lanteri P, Gerosa M: Surgery for intramedullary spinal cord tumors: the role of intraoperative (neurophysiological) monitoring. Eur Spine J 16 (Suppl 2):S130-S139, 2007

33. Sarnthein J, Hejrati N, Neidert MC, Huber AM, Krayenbühl $\mathrm{N}$ : Facial nerve motor evoked potentials during skull base surgery to monitor facial nerve function using the thresholdlevel method. Neurosurg Focus 34(3):E7, 2013

34. Schmitt WR, Daube JR, Carlson ML, Mandrekar JN, Beatty CW, Neff BA, et al: Use of supramaximal stimulation to predict facial nerve outcomes following vestibular schwannoma microsurgery: results from a decade of experience. J Neurosurg 118:206-212, 2013

35. Sutter M, Eggspuehler A, Grob D, Jeszenszky D, Benini A, Porchet F, et al: The diagnostic value of multimodal intraop- 
erative monitoring (MIOM) during spine surgery: a prospective study of 1,017 patients. Eur Spine J 16 (Suppl 2):S162S170, 2007

36. Szelényi A, Hattingen E, Weidauer S, Seifert V, Ziemann $\mathrm{U}$ : Intraoperative motor evoked potential alteration in intracranial tumor surgery and its relation to signal alteration in postoperative magnetic resonance imaging. Neurosurgery 67:302-313, 2010

37. Verla T, Fridley JS, Khan AB, Mayer RR, Omeis I: Neuromonitoring for intramedullary spinal cord tumor surgery. World Neurosurg 95:108-116, 2016

\section{Disclosures}

The authors report no conflict of interest concerning the materials or methods used in this study or the findings specified in this paper.

\section{Author Contributions}

Conception and design: Takeshima. Acquisition of data: Matsuoka, Hayashi, Takatani. Analysis and interpretation of data: Takeshima. Drafting the article: Takeshima, Matsuoka, Hayashi, Motoyama. Critically revising the article: Hayashi. Reviewed submitted version of manuscript: Nishimura, Nakagawa, Motoyama, Park. Approved the final version of the manuscript on behalf of all authors: Takeshima. Statistical analysis: Takeshima. Study supervision: Kawaguchi, Nakase.

\section{Correspondence}

Yasuhiro Takeshima: Nara Medical University School of Medicine, Nara, Japan.takeshim@naramed-u.ac.jp. 